\title{
Influence of Solutionising and Aging Treatments on Mechanical Behavior of Stir-Cast Eutectoid Steel Powder Reinforced Al 7075 Metal Matrix Composites
}

\author{
Rajesh, Sathyashankara Sharma* and M. C. Gowrishankar
}

\author{
Department of Mechanical and Manufacturing Engineering, \\ Manipal Institute of Technology, Manipal Academy of Higher Education, \\ Manipal, Karnataka, India, 576104 \\ *Email: ss.sharma@manipal.edu \\ Phone: 9740540928; Fax: 91-820-2571071
}

\begin{abstract}
Al 7075 is a good choice as a matrix material to prepare metal matrix composites (MMCs) owing to its better specific tensile strength and toughness. Among different types of the recently introduced composite materials, particles reinforced MMC and in particular aluminium as matrix material have been found to have enormous industrial applications like automotive and aerospace sectors. In the present study, mechanical properties of $\mathrm{Al} 7075$-eutectoid steel powder metal matrix composites is assessed in age-hardened and as-cast conditions. The heat treatment processes are carried out in atmospheric condition. Eutectoid steel (water hardenable tool steel - W1grade) reinforced aluminium 7075 is an attempt to investigate the role of micro-constituent phases on property alterations of metal matrix composites. As an economical and promising route for $\mathrm{MMC}$, liquid stir casting technique is used to reinforce synthesised steel powder in the matrix of $\mathrm{Al} \mathrm{7075.} \mathrm{Heat} \mathrm{treatment} \mathrm{is} \mathrm{performed} \mathrm{as} \mathrm{a} \mathrm{tool} \mathrm{to} \mathrm{mould}$ and improve the required mechanical properties as per the requirements. Eutectoid steel powder is selected as the reinforcement material since it is believed to be composed of lamellar pearlite with ferrite and cementite as alternate layers in as-cast condition, serving as micro-hybrid reinforcement to improve hardness and strength. In this work four different proportions of steel powder (2, wt.\% 4 wt.\% and 6 wt.\%) reinforced composites are prepared by a two-stage stir casting process. Age-hardening treatment is given to the samples and analysed critically and compared with alloy matrix for different properties such as tensile strength, hardness and toughness. Results have shown significant improvement in the ultimate tensile strength and hardness of the composites after aging treatment. The $4 \mathrm{wt} . \%$ steel powder reinforced composite has shown better results compared to other composites.
\end{abstract}

Keywords: Metal matrix composites; eutectoid steel; liquid stir casting; age hardening.

\section{INTRODUCTION}

Conventional materials like pure metals and alloys have restrictions to achieve combinations of strength, stiffness and density. In order to overwhelm these shortcomings, metal matrix composites (MMCs) entered the material world as new class of materials. The matrix chosen is usually a light weight material (such as aluminium, magnesium and titanium) with good specific tensile strength and chemical inertness. The reinforcement for these materials is usually ceramics, alloys or light 
materials to possess balanced stiffness, strength and density. The reinforcement materials are usually $\mathrm{SiC}, \mathrm{Al}_{2} \mathrm{O}_{3}, \mathrm{~B}_{4} \mathrm{C}, \mathrm{TiC}, \mathrm{TiB}_{2}$ and graphite [1-4].

Aluminium and its alloys have a large range of applications in the present market due to durability and compositional consistency. The 7XXX series are heat treatable, possess high strength, tougher and corrosion-resistant alloys. Aluminium 7075 has good machining ability, higher tensile strength and fatigue resistance. The poor tribological property problem may be overcome due to the tailorability of blended properties by intentional heat treatment $[5,6]$.

Enhancement of aluminum alloys had been focused on secondary precipitation mechanism of intermetallics, in which the precipitates formed from a non-equilibrium phase are responsible for the matrix hardening by artificial aging in an alloy system [7,8]. Solution treatment and high temperature aging of an Al 7075 alloy reinforced with harder particulates showed that the optimum aging temperature, above which effective hardening is not observable, appeared to depend on the dispersion density as well as the amount of intermetallics formed. Studies on solution treatment and artificial aging of commercially produced $\mathrm{Al} 7 \mathrm{XXX}, \mathrm{Al} 6 \mathrm{XXX}, \mathrm{Al} 2 \mathrm{XXX}$ composites revealed a significant increase in tensile properties and unwanted reduction in ductility with optimum aging kinetics $[9,10]$. The excellent increase in hardness related characteristics was attributed to the additional dislocation density introduced in the matrix due to the coefficient of thermal expansion mismatch of the matrix and reinforcement $[11,12]$.

The use of Al-Zn-Mg (Al 7XXX) alloys for manufacturing MMC leads to the formation of intermetallic $\mathrm{Mg}_{2} \mathrm{Zn}$ and $\mathrm{Mg}_{3} \mathrm{Zn}_{3} \mathrm{Al}_{2}$ in the metal matrix [13,14]. These hard and brittle phases formed between chemically dissimilar metals surrounding the reinforcement as a continuous phase may be highly malicious to the durability of the MMC component. This condition must be avoided, either by eradicating coring in the matrix as well as by controlling the rates of nucleation and crystal growth to promote spontaneous precipitation of ultra-fine well dispersed intermetallics in the alloy matrix [15]. In the alloy magnesium serves as a wetting agent and intermetallic forming phase with aluminum and zinc to result in a clean and strong interface.

The present study was undertaken with the objective of evaluating the influence of solution treatment and precipitation sequence of eutectoid steel powder reinforced $\mathrm{Al}$ 7075 MMCs regarding microstructure, tensile properties and hardness. The MMC must have good machinability along with high strength-to-weight ratio, hence dispersion of reinforcement and intermetallics as well as number and fineness of intermetallics act as a representative role in property enhancement and machinability.

\section{EXPERIMENTAL DETAILS}

Table 1 and 2 show the composition of the base material Al 7075 and eutectoid steel reinforcement, respectively. Composites with different weight percentage of the reinforcement material (steel powder size range was 55-70 $\mu \mathrm{m}$ ) were successfully cast.

Table 1. Chemical composition of Al 7075.

\begin{tabular}{lcccccccc}
\hline Element & $\mathrm{Cu}$ & $\mathrm{Mg}$ & $\mathrm{Mn}$ & $\mathrm{Fe}$ & $\mathrm{Cr}$ & $\mathrm{Si}$ & $\mathrm{Zn}$ & $\mathrm{Al}$ \\
\hline wt.\% & 1.63 & 2.52 & 0.074 & 0.18 & 0.22 & 0.06 & 5.62 & $\mathrm{Bal}$. \\
\hline
\end{tabular}


Table 2. Chemical composition of eutectoid steel reinforcement.

\begin{tabular}{lcccccccc}
\hline Element & $\mathrm{C}$ & $\mathrm{Mn}$ & $\mathrm{Cr}$ & $\mathrm{Mo}$ & $\mathrm{Si}$ & $\mathrm{P}$ & $\mathrm{S}$ & $\mathrm{Fe}$ \\
\hline $\mathrm{wt} \%$ & 0.81 & 0.13 & 0.24 & 0.15 & 0.28 & 0.1 & 0.08 & Bal. \\
\hline
\end{tabular}

The composites were cast in liquid metallurgy route via stir casting technique. The aluminium 7075 alloy billets were purchased from 'Perfect Metal Works' Bengaluru. The W1 grade tool steel billets were purchased from the vendor and subjected to chemical analysis, preheated to remove moisture and hardened by heating to $750{ }^{\circ} \mathrm{C}$, and followed by water quenching to room temperature. The quenched pieces were surface ground to collect debris and further pulverised into fine powders by ballgrinding mill, and sieved to get the finest $(55-70 \mu \mathrm{m})$ powder. The Al 7075 billets are introduced into the crucible as the temperature of the crucible is increased to $820{ }^{\circ} \mathrm{C}$. The system was held isothermally at $820{ }^{\circ} \mathrm{C}$ to ensure complete melting. Next, hexachloro ethane $\left(\mathrm{C}_{2} \mathrm{Cl}_{6}\right)$ tablets were introduced for degassing of trapped gases in the melt and impurities (i.e. in the form of slag) which are skimmed out during manual stirring of the melt. The stirrer was actuated and the melt in the crucible was stirred; and the processing parameters (depth of stirrer in the melt $=2 / 3$ distance below the melt surface, speed of the stirrer $=400 \mathrm{rpm}$ ) were standardised to form a symmetrical vortex in the pool around the stirrer and preheated $\left(300^{\circ} \mathrm{C}, 1\right.$ hour $)$ eutectoid steel powder was slowly introduced into the vortex of the molten metal. The stirring was continued for 5 minutes to confirm uniform distribution of the powder in the melt. During the addition of the powder the melt was maintained in the liquid state at temperature ranging from 750 to $720{ }^{\circ} \mathrm{C}$ for better dispersion of iron powder in the melt. This was followed by mechanical stirring for 5 minutes at $800{ }^{\circ} \mathrm{C}$. The melt was poured at this high temperature into the preheated steel moulds which were maintained at room temperature. Four different iron powder ( 2 wt. $\%, 4$ wt.\% and 6 wt.\%) reinforced composites were obtained after air cooling.

The cast specimens are first homogenised at $550{ }^{\circ} \mathrm{C}$ for 12 hours in resistance heating furnace. Homogenisation allows good distribution of solute atoms in the base metal dendrites to establish the same chemical composition throughout the casting. The ASTM E8M and ASTM 18-02 specimens are prepared for tensile and hardness tests, respectively. The specimens are age hardened with solutionised annealing as the first step and followed by aging. Solutionising is carried out in resistance heating furnace at $550{ }^{\circ} \mathrm{C}$ for 2 hours. The specimens are then quenched in distilled water bath and tracked by aging in hot air oven at two different temperatures, $100{ }^{\circ} \mathrm{C}$ and $200{ }^{\circ} \mathrm{C}$. The hardness distribution graphs at both aging temperatures with respect to time are plotted.

Micro Vickers hardness test with dead weight of $100 \mathrm{kgf}$ was employed to test the hardness of the specimen. Tensile test specimens are prepared as per the dimension of ASTM E 8 standard. A computerised tensometer with load cell value kept at $20.5 \mathrm{kN}$, test mode as break, length increment value as $0.05 \mathrm{~mm}$ and with the cross head speed of $2 \mathrm{~mm} / \mathrm{min}$ was used to perform the tensile test. The load versus deformation graphs were obtained and ultimate tensile strength is recorded.

The composites produced were examined by an optical microscope to analyse the dispersion of reinforcements in the matrix. A cylindrical sample of diameter $10 \mathrm{~mm}$ and height $15 \mathrm{~mm}$ is cut from the castings, which is rough ground by belt polisher followed by polishing with 5 different grades of emery papers one-by-one starting from 1000 to 100 microns in steps of 200 microns. The mirror-like polished surface after rinsing in cold water was subjected to final fine polishing with a diamond paste 
embedded velvet clothed polishing disc. After etching in Nital they were examined for microstructure under optical microscope at different magnifications.

\section{RESULTS AND DISCUSSION}

The results of all the tests conducted were recorded in the form of tables and graphs. For microstructure analysis the microphotographs were taken to analyse the distribution of reinforcements in Al 7075 eutectoid steel powder composite. Hardness and charpy impact strength tests were carried out to study the effect of reinforcement. A tensile test was conducted to find out the ultimate tensile strength of the composite material. The results were discussed with proper explanation in each case and finally concluded based on the results obtained. For tensile test the average of three test trials were considered as the experimental outcome.

\section{Hardness Properties}

A precipitation hardening treatment was carried out and hardness variation at different time intervals while aging isothermally at two temperatures for different composites was plotted. The specimens were solutionised first in the muffle furnace for 2 hours at $550{ }^{\circ} \mathrm{C}$ and water quenched to room temperature. Quenched specimens were aged at 100 ${ }^{\circ} \mathrm{C}$ and $200{ }^{\circ} \mathrm{C}$ isothermally until the increase in hardness was stopped so that the hardness distribution curve is continuously descending. Such graphs are shown in Figure 1, 2, 3 and 4. The peak hardness obtained in respective graphs is recorded for different temperatures in each composite.

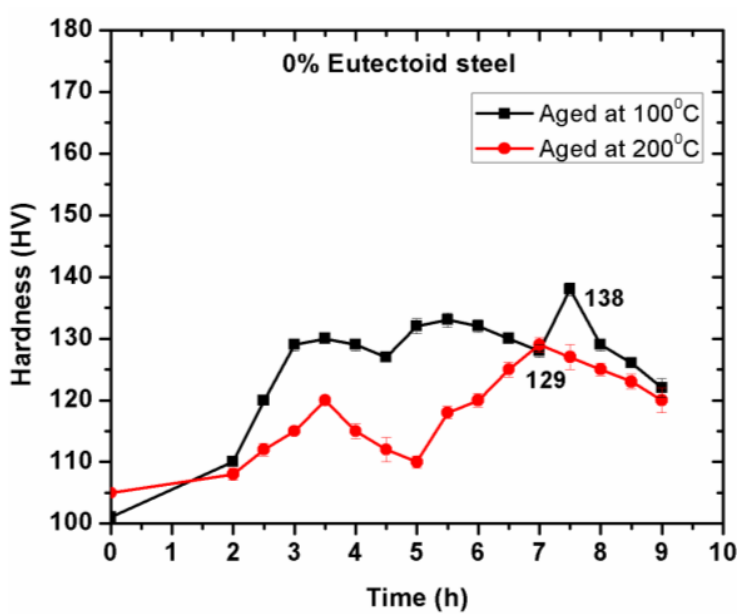

(a)

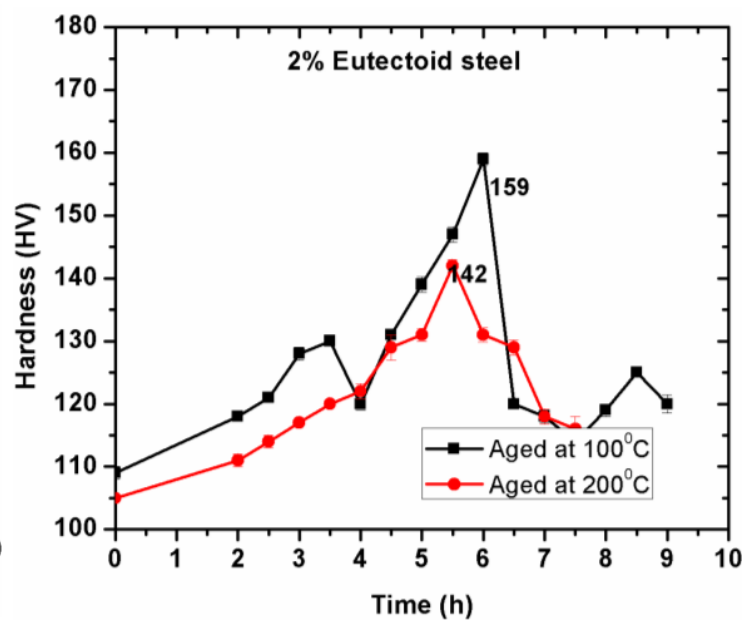

(b)

Figure 1. Variation of hardness of (a) alloy and; (b) $2 \%$ steel powder reinforced composite with respect to aging time at different temperatures. 


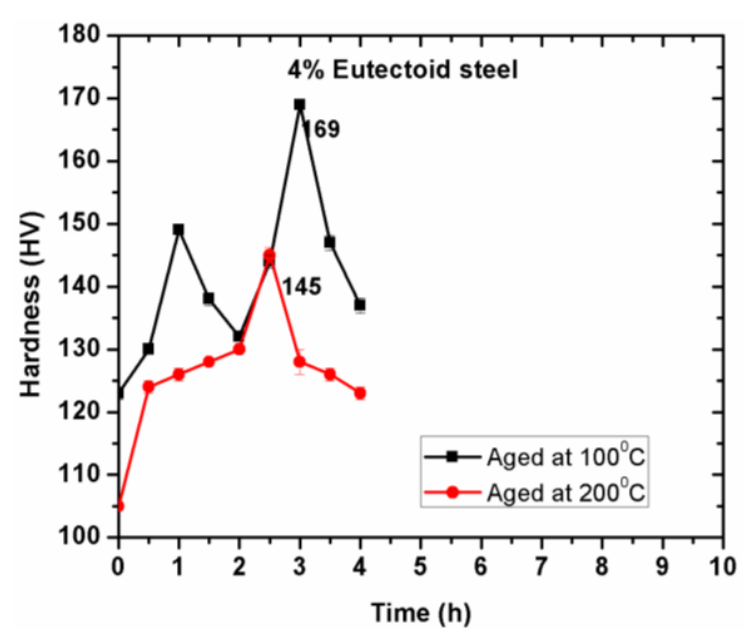

(a)

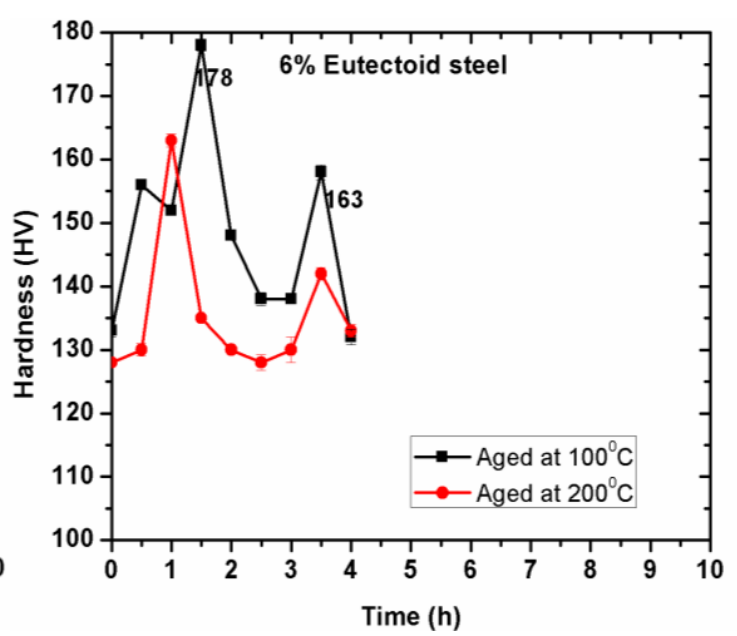

(b)

Figure 2. Variation of hardness of composite with (a) $4 \%$ and; (b) $6 \%$ of steel powder reinforced with respect to aging time at different temperatures.

Figure 3 represents the bar charts of peak hardness values obtained from Figure 1(a) and 1(b), and Figure 2(a) and 2(b). Lower aging temperature shows better hardness over other two conditions in each materials followed by least in as-cast condition. Figure 4 shows bar charts of peak aging durations in hours obtained from Figure 1(a) and 1(b), and Figure 2(a) and 2(b).

More lowering of the aging temperature will achieve peak hardness, however the longer is the duration required to achieve that peak value. This is due to the increase in metastable transition precipitate zones during the lower aging temperatures. Since the aging kinetics is slow at lower aging temperature, the time required for achieving peak value is also longer [1]. At the same time higher hardness values were recorded for the composites with higher amount of reinforcement addition, however aging process for peak aging requires lesser duration compared with the same aging parameter condition due to the increase in nucleation spots for precipitation [2].

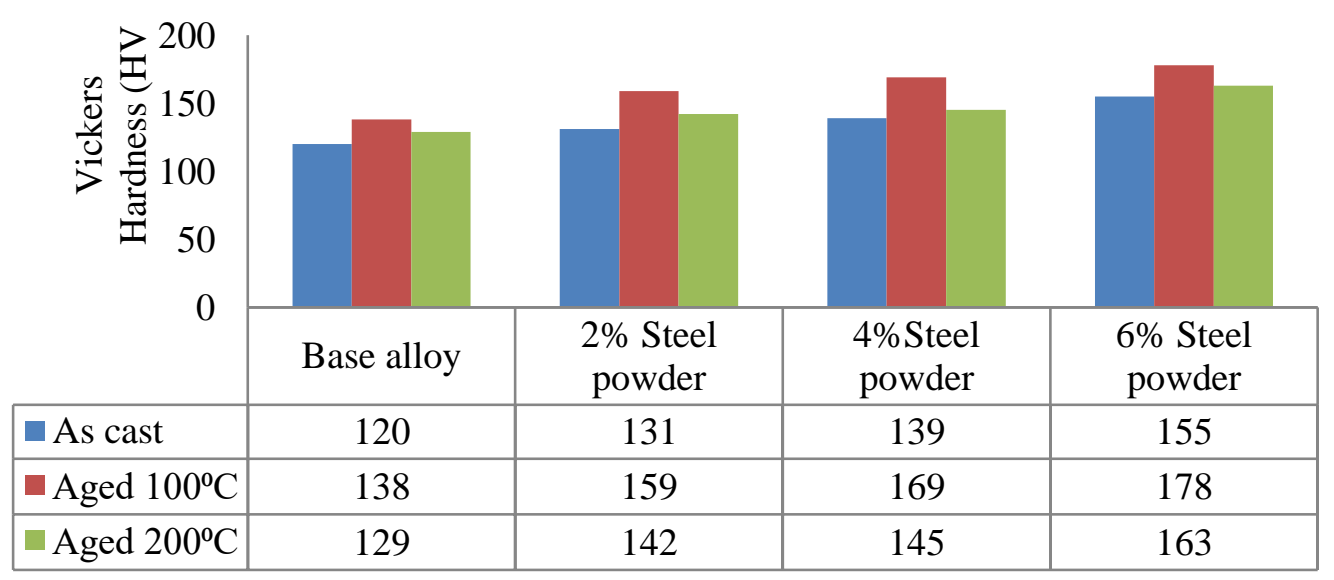

Figure 3. Comparison of peak hardness with variation in temperature for different composites. 


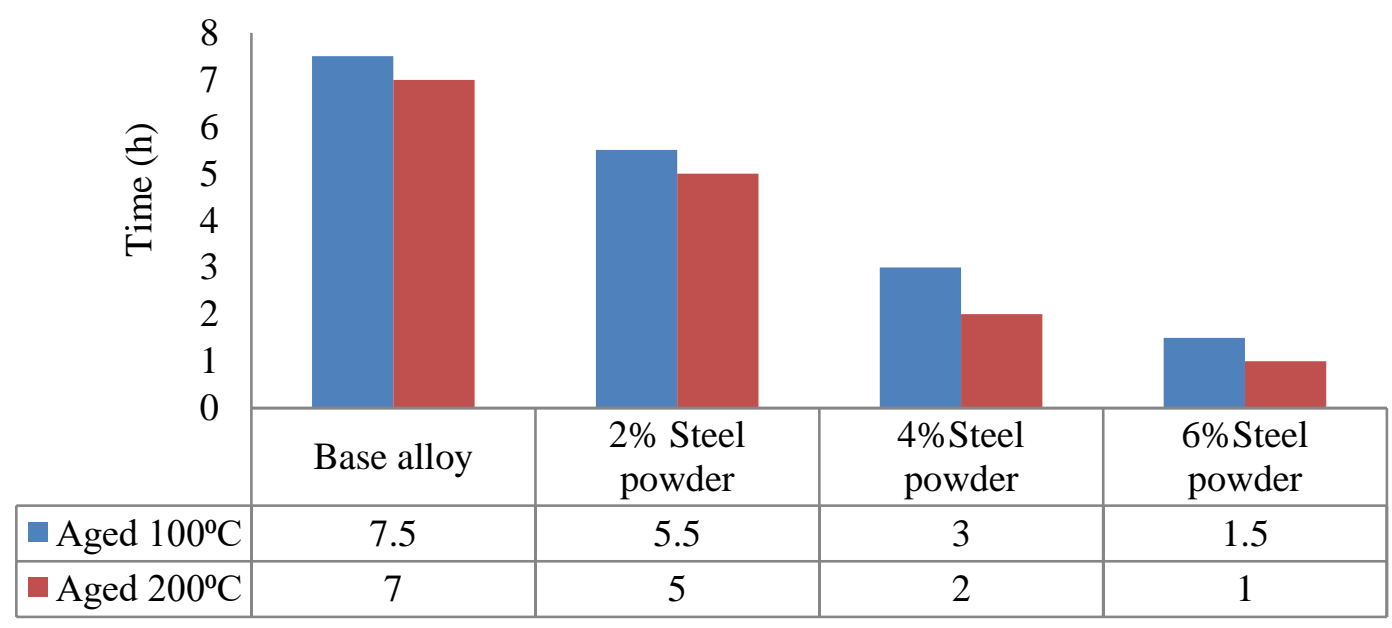

Figure 4. Comparison of peak aging durations at different aging temperatures for different composites.

\section{Tensile Properties}

The ultimate tensile strength of as-cast and age-hardened specimens is plotted in the graph as shown below. Similar trend is observed in tensile test. The $4 \mathrm{wt} \%$ reinforced composite specimen indicates excellent UTS compared to other categories. Surprisingly, $6 \mathrm{wt} \%$ reinforced composite illustrates slightly poor UTS compared to other counterparts. It may be due to the improper bonding (wettability) of the steel reinforcement with nonferrous matrix alloy, due to which the bond strength of the composite is lacking as the reinforcement quantity is above the permissible (4 wt.\%) value [14]. Like hardness value, tensile property of peak aged specimen at lower aging temperature shows better UTS compared to higher aging temperature (Figure 5). This may be due to the increase in misfit strain caused by the difference in coefficient of thermal expansion between matrix and reinforcement with decrease in aging temperature.

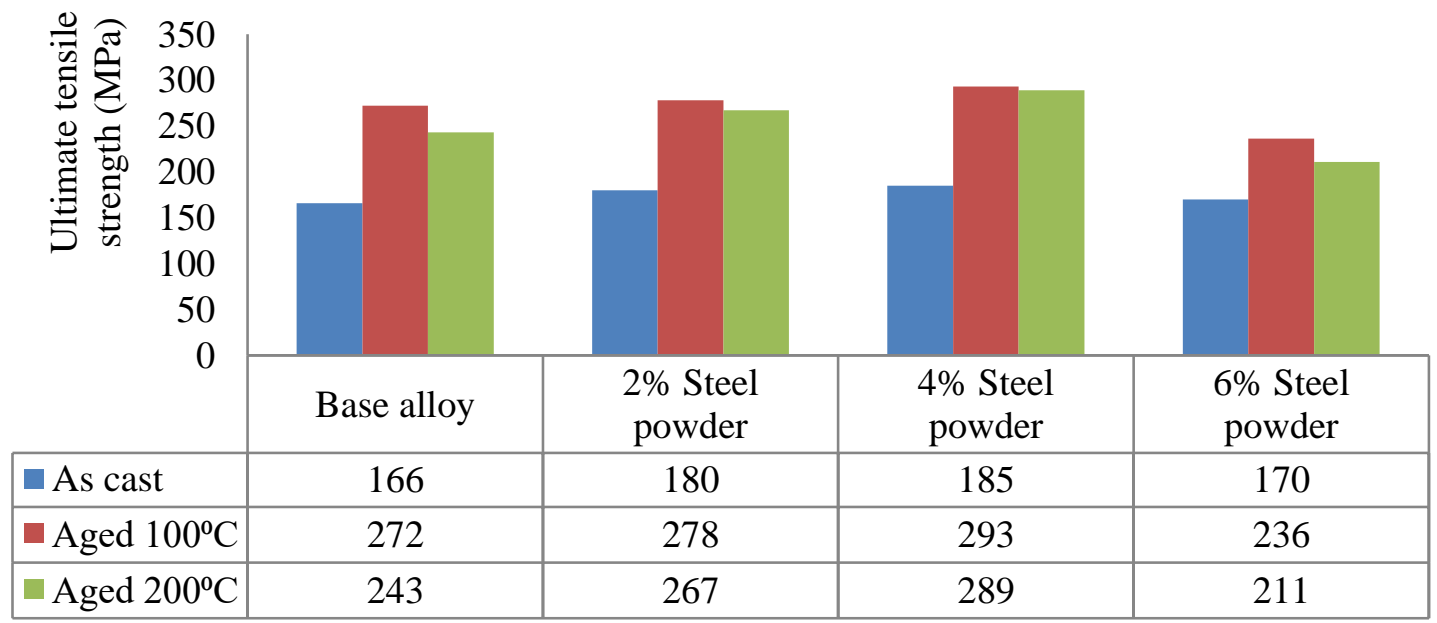

Figure 5. Comparison of UTS with variation in temperature for different composites. 


\section{Microstructural Study}

Microstructure obtained from the scanning electron microscope for the different specimens under consideration is shown in Figure 6. From the microstructure analysis, it is seen that reinforcements are evenly distributed in the matrix. There is no random accumulation of the reinforcement particles at any particular spot. The superior mechanical properties obtained for the material is due to the uniform dispersion of steel reinforcement in the aluminium metal matrix. There is no segregation of particles.

Increasing the amount of reinforcement increased the strain incurred in the matrix due to the difference in the thermal expansion coefficient between the matrix and reinforcement, which helps to enhance the dislocation density in the composite. The interaction between the reinforcement, precipitating intermetallics and dislocation creates synergetic atmosphere to accelerate the aging process with considerable heap in hardness and strength [14]. The aging rate enhances with the increase in the amount percentage of reinforcement in the composite. This contributes to improving the mechanical properties of the composites after the aging treatment.

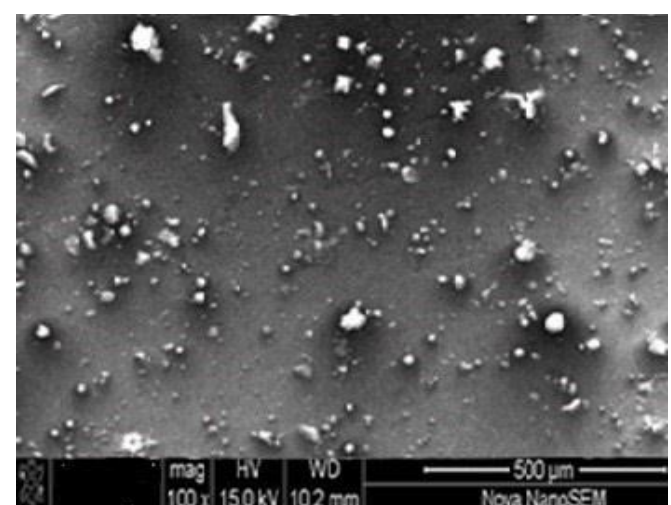

(a)

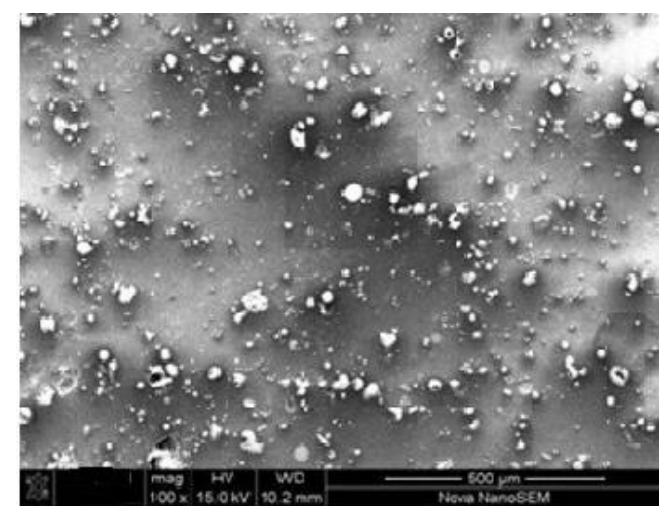

(b)

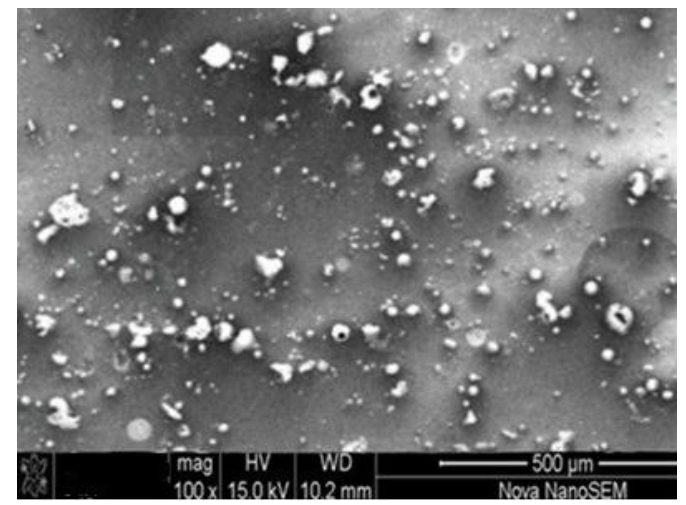

(c)

Figure 6. SEM micrograph of composites with (a) 2 wt. $\%$, (b) 4 wt. $\%$ and; (c) 6 wt. $\%$ of steel reinforcement.

\section{CONCLUSION}

This study presents the effect of artificial aging on hardness properties of composites. When evaluating the age hardening of composites, this study identifies its hardness behavior in two different aging temperatures with time. This analysis leads to the 
conclusion that lower aging temperature $\left(100{ }^{\circ} \mathrm{C}\right)$ seems to be ideal with respect to aging time and increment in hardness. The following conclusions are attained as the research output.

i. Hardness of composites which are given aging treatment at lower temperature range improves by $25 \%$ compared to as-cast material.

ii. Ultimate tensile strength of the $4 \mathrm{wt} \%$ steel powder reinforced composite has shown $50 \%$ improvement after the aging treatment.

iii. Microstructure analysis has shown evenly distributed reinforcement particles in the matrix which is responsible for the improvement in the mechanical properties.

iv. A $4 \mathrm{wt} \%$ reinforced composite emerges as the best composite in the selected group having optimum combination of strength and hardness.

\section{REFERENCES}

[1] Rebba B, Ramanaiah N. Studies on mechanical properties of 7075 Al-B4C composites. Advanced Materials Manufacturing \& Characterization 2014; 4: 42-46.

[2] Mahendra Boopathi M, Arulshri KP, Iyandurai N. Evaluation of mechanical properties of aluminium alloy2024 reinforced with silicon carbide and fly ash hybrid metal matrix composites. American Journal of Applied Sciences 2013; 10: 219-229.

[3] Poovazhagan L. Abrasive wear behaviour of aluminium hybrid nanocomposites produced by ultrasonication assisted casting method. International Journal of Automotive and Mechanical Engineering 2017; 14: 4561-4573.

[4] Donthamsetty S, Babu PS. Experiments on the wear characteristics of A356 MMNCs fabricated using ultrasonic cavitation. International Journal of Automotive and Mechanical Engineering 2017; 14: 4589-4602.

[5] Sameezadeh M, Emamy M, Farhangi H. Effects of particulate reinforcement and heat treatment on the hardness and wear properties of AA 2024-MoSi2 nanocomposites. Materials and Design 2011; 32: 2157-2164.

[6] Rebba B, Ramanaiah N. Evaluation of mechanical properties of aluminium alloy (Al-2024) reinforced with molybdenum disulphide (MOS2) metal matrix composites. Procedia Materials Science 2014; 6: 1161-1169.

[7] Surappa MK. Aluminium matrix composites: Challenges and opportunities. Sadhana 2003; 28: 319-334.

[8] Singla M, Dwivedi DD, Singh L, Chawla V. Development of aluminium based silicon carbide particulate metal matrix composite. Journal of Minerals and Materials Characterization and Engineering 2009; 08: 455-467.

[9] Mathur S, Barnawal A. Effect of process parameter of stir casting on metal matrix composites. International Journal of Science and Research 2013;2:395398.

[10] Das S, Das S, Das K. Ageing behavior of Al-4.5 wt\% Cu matrix alloy reinforced with $\mathrm{Al} 2 \mathrm{O} 3$ and $\mathrm{ZrSiO} 4$ particulate varying particle size. Journal of Materials Science 2006;41:5402-5406.

[11] Kerti I, Toptan F. Microstructural variations in cast B4C-reinforced aluminium matrix composites (AMCs). Materials Letters 2008; 62: 1215-1218.

[12] Toptan F, Kilicarslan A, Karaaslan A, Cigdem M, Kerti I. Processing and microstructural characterisation of AA 1070 and AA 6063 matrix B4Cp 
reinforced composites. Materials and Design 2010;32:87-91.

[13] Shankar G, Jayashree PK, Shetty R, Kini A, Sharma SS. Individual and combined effect of reinforcements on stir cast aluminium metal matrix composites-A Review. International Journal of Current Engineering and Technology 2013; 3: 922-934.

[14] Kok M. Production and mechanical properties of Al2O3 particle-reinforced 2024 aluminium alloy composites. Journal of Materials Processing Technology 2005; 161: 381-387.

[15] Veeresh Kumar GB, P Rao CS, Selvaraj N, Bhagyashekar MS. Studies on Al6061-SiC and Al7075-Al2O3 Metal Matrix Composites. Journal of Minerals \& Materials Characterization \& Engineering 2010;9:43-55. 